\title{
Computer-Assisted Virtual Surgical Planning for Segmental Mandibular Reconstruction with Iliac Crest Free Flap
}

\author{
A Assoumane ${ }^{1,2}$, K Liü2 ${ }^{2}$ Z Shao ${ }^{1,2 *}$, Z J Shang² and L Qing \\ Wuhan University, China \\ ${ }^{2}$ Department of Oral and Maxillofacial -Wuhan University, China \\ ${ }^{3}$ Central Hospital of Enshi Autonous Prefecture of Hubei Province, China
}

${ }^{1}$ The State Key Laboratory Breeding Base of Basic Science of Stomatology (Hubei-MOST) and Key Laboratory for Oral Biomedicine Ministry of Education,

Submission: February 23, 2018; Published: March 15, 2018

*Corresponding author: Z Shao, Department of Oral and Maxillofacial, Head and Neck Oncology, School and Hospital of Stomatology, Wuhan University, 237 Luoyu Road Wuhan 430079 China, Tel: 86-27-87686215; Email: shaozhe@whu.edu.cn

\begin{abstract}
Segmental mandibular reconstruction remains a challenge for the head and neck surgeons. The Iliac crest free flap is widely used for mandibular reconstruction. It often leads to being the best functional and esthetic results in a conventional surgery based on the surgeon's experience. We used a computer-assisted virtual surgical planning for Brown's class I (lateral effects) type segmental mandibular reconstruction to repair these defects. We reviewed records of 42 patients with a mandibular tumour who underwent mandibulectomy and reconstruction using a vascularized iliac crest free in our Hospital. Conventional surgery was used in twenty-eight (28) patients while 14 patients underwent computer-assisted virtual surgical planning, referring to computer-aided design (CAD) and modelling/rapid prototyping. The overall flap survived successfully without any complications in both groups. Clinical outcomes of all patients were satisfactory postoperative. The days of staying in the hospital and operation time for the two groups of patients were compared and outcomes of the two types of surgery were evaluated.
\end{abstract}

Those in computer-assisted group presented a short time of operation than conventional surgery $(7.00 \pm 1.62) /(8.61 \pm 1.40)$ respectively with a P value: $(\mathrm{p}=0.002)$. However, for patients that underwent conventional surgery, the days of staying declined than of a computer-assisted surgery $(17.32 \pm 4.78) /(21.21 \pm 3.53)$ with $(\mathrm{P}=0.010)$. Computer-assisted virtual surgical planning can be done to the satisfaction of the patient using the iliac crest flap and conventional surgery. With the experience of the surgeon's osteotomy with freehand, good results were achieved. However, in our experience the best indication for computer- assisted surgery should be for the benign tumour with clear margins.

Keywords: Conventional surgery; lliac crest free flap; Computer assisted virtual surgical Planning

\section{Introduction}

Segmental mandibular reconstruction remains challenging for the head and neck surgeons. Recently, Brown and his colleagues [1] proposed a new classification of mandible defects based on the four corners of the mandible (two angles and two canines): Class I (Lateral), class II (Hemim and ibulectomy), Class III (anterior), and Class IV (extensive). Lateral defects of the mandible were defined as those that extended from the anterior ramus of the mandible to the ipsilateral para symphysis. Furthermore, bone reconstruction of the lateral mandible is not mandatory for speech or swallowing functions but it leads to the best functional and esthetic results. Several vascularized muscle-osseous flaps can be used depending on the bone and soft tissue defects to be reconstructed which include the iliac crest flap, fibula flap and scapula. The fibula flap can be used to reconstruct the segmental mandibular defects longer than 14 $\mathrm{cm}$ and a reliable skin paddle can be harvested with the flap for reconstruction of soft tissue.

The drawback of this flap is the height of the boneless than that of native mandible [2]. The iliac crest flap is the only one that enables reconstruction of the initial heights and width of the mandible. It is more favourable than the fibula flap for some surgeons because of the large amount of bone volume, rich cancellers blood supply, and compact cortex, which make it an ideal choice for plate fixation and implant placement for dental restoration $[3,4]$. However, it cannot be used to reconstruct defects longer than $14 \mathrm{~cm} \mathrm{5}$. Since 1980, the technique of computer-aided design (CAD)/ (CAD) has been extensively applied and significantly facilitates orthopaedic surgery, plastic 


\section{Global Journal of Otolaryngology}

surgery and Oral and Maxillofacial Surgery. Computer-assisted virtual surgical planning here referred to as computer-aided design (CAD) and modelling/rapid prototyping, is becoming increasingly popular in the field of complex cranio maxillofacial reconstruction.

The advantages of using the virtual technology allow improving surgical precision and decreasing operation time and associated complications. We used a computer - assisted virtual surgical planning only for Brown's class I type segmental mandibular reconstruction using iliac crest free flap. The aim of this study is to show our experience of mandibular reconstruction with iliac crest free flap by virtual surgical planning and compare it with conventional surgery based on surgeon's experience using the freehand osteotomy method.

\section{Patients and Methods}

Forty-two (42) patients (24males and 18 females), underwent segmental resection and reconstructed with iliac crest free flap in our Hospital. Clinical data was collected by demographic information (age, sex), sites of defects, tumours loading resection and complications of donor sites encountered. All patients who required reconstruction of lateral mandibular defects due to benign tumours, malignant diseases and traumatic defects were divided into the following two groups: Those on basis of reconstructive method for computer-assisted virtual surgical planning were 14 patients and the other 28 patients treated with conventional surgery based on the surgeon's experiences with freehand osteotomies and own judgment of method for reconstruction defects. The indication for resection of lateral mandible for 3D planning was: sarcoma $(n=1$, 7.14\%); recurrence of adenoid cystic carcinoma ( $n=1,7.14 \%)$; ameloblastoma (n=6, 42.86\%); keratocystic odontogenic tumor $(n=3,21.43 \%)$; ossifying fibroma $(n=1,7.14 \%)$; Myoepithelioma ( $n=1,7.14 \%)$; traumatic defect $(n=1,7.14 \%)$. While for conservative surgery was: ameloblastoma( $n=11,39.29 \%)$; ossifying fibroma ( $n=9,32.14 \%)$; keratocystic odontogenic tumor $(\mathrm{n}=2,7.14 \%)$; odontogenic fibroma $(\mathrm{n}=1,3.57 \%) ;$ odontoma( $\mathrm{n}=1$, $3.57 \%)$; neurofibromatosis $(n=1,3.57 \%)$; fibro myxoma $(n=1$, $3.57 \%)$; osteomyelitis $(n=1,3.57 \%)$ and pathological fracture $(n=1,3.57 \%)$.

The site of defects was classified as described by Brown's new classification after oncological resection in the two groups for reconstruction of lateral mandibular defects. In computerassisted surgery, all patients were classified as class I type segmental mandible (left and right side of defects with a total of 14 patients) and for conventional surgery group 13 patients were class I; 3 patients were Class II Type of defects; 9 patients were class III types and 3 patients were class IV type (see in Table 1). However, in this study, we excluded patients with class II, III and IV in the group of conventional surgery due to similar groups in order to have a meaningful contribution to the results. This study was approved by the institutional review board of the hospital and informed consent has been obtained.
Table1: Characteristic of 42 patients treated with computer-assisted virtual surgical planning and conventional surgery for segmental mandibular reconstruction with Iliac Crest free flap.

\begin{tabular}{|c|c|c|c|c|c|c|}
\hline \multirow[t]{2}{*}{ Variables } & \multicolumn{2}{|c|}{ CS } & \multicolumn{2}{|c|}{ CA } & \multirow[t]{2}{*}{$\chi^{2}$} & \multirow[t]{2}{*}{$\mathbf{P}$} \\
\hline & $\mathrm{N}=\mathbf{2 8}$ & $\%$ & $\mathrm{~N}=14$ & $\%$ & & \\
\hline \multicolumn{7}{|l|}{ Sex } \\
\hline male & 16 & 57.14 & 8 & 57.14 & 0 & 1 \\
\hline female & 12 & 42.86 & 6 & 42.86 & & \\
\hline \multicolumn{7}{|l|}{ Diagnosis } \\
\hline Ameloblastoma & 11 & 39.29 & 6 & 42.86 & & \\
\hline KCOT & 2 & 7.14 & 3 & 21.43 & & \\
\hline $\begin{array}{l}\text { Ossifying } \\
\text { fibroma }\end{array}$ & 9 & 32.14 & 1 & 7.14 & & \\
\hline Sarcoma & 0 & 0 & 1 & 7.14 & & \\
\hline $\begin{array}{l}\text { Recurrence of } \\
\text { Adenocystic } \\
\text { carcinoma }\end{array}$ & 0 & 0 & 1 & 7.14 & & \\
\hline Traumatic Defect & 0 & 0 & 1 & 7.14 & & \\
\hline Myoepithelioma & 0 & 0 & 1 & 7.14 & & \\
\hline $\begin{array}{l}\text { Odontogenic } \\
\text { fibroma }\end{array}$ & 1 & 3.57 & 0 & 0 & & \\
\hline Odontoma & 1 & 3.57 & 0 & 0 & & \\
\hline $\begin{array}{l}\text { Pathological } \\
\text { fracture }\end{array}$ & 1 & 3.57 & 0 & 0 & & \\
\hline $\begin{array}{c}\text { Neurofibro- } \\
\text { matosis }\end{array}$ & 1 & 3.57 & 0 & 0 & & \\
\hline Fibromyxoma & 1 & 3.57 & 0 & 0 & & \\
\hline OSTEOMYELITIS & 1 & 3.57 & 0 & 0 & 14.311 & 0.137 \\
\hline \multicolumn{7}{|l|}{$\begin{array}{l}\text { lateral } \\
\text { mandibular of } \\
\text { defects }\end{array}$} \\
\hline Class I left side & 5 & 17.86 & 7 & 50 & & \\
\hline Class I Right side & 8 & 28.57 & 7 & 50 & & \\
\hline Class II & 3 & 10.71 & 0 & 0 & & \\
\hline Class III & 9 & 32.14 & 0 & 0 & & \\
\hline \multirow[t]{3}{*}{ Class IV } & 3 & 10.71 & 0 & 0 & 12.075 & 0.017 \\
\hline & \multicolumn{2}{|c|}{ CS } & \multicolumn{2}{|c|}{ CA } & $\mathbf{t}$ & $\mathbf{P}$ \\
\hline & \multicolumn{4}{|c|}{$(x \pm s)$} & & \\
\hline ages & \multicolumn{2}{|c|}{$38.50 \pm 14.74$} & \multicolumn{2}{|c|}{$30.07 \pm 13.72$} & 1.787 & 0.082 \\
\hline operation time & \multicolumn{2}{|c|}{$8.61 \pm 1.40$} & \multicolumn{2}{|c|}{$7.00 \pm 1.62$} & 3.335 & 0.002 \\
\hline days & \multicolumn{2}{|c|}{$17.32 \pm 4.78$} & \multicolumn{2}{|c|}{$21.21 \pm 3.53$} & -2.696 & 0.01 \\
\hline
\end{tabular}

\section{Preoperative Virtual Surgical Planning}

All the patients in the group of computer-assisted surgery underwent pre operative virtual planning. A high-resolution helical computer tomography (CT scan) of the mandible and iliac crest bone were performed (field of view: $153.60 \mathrm{~mm}$; slice thickness: $0.3 \mathrm{~mm}$; width and height: $512 \times 512$; pixel size: $0.3 \mathrm{~mm}$; Scanner: NIM/NTVGMARK3, $110 \mathrm{KV} 0.07 \mathrm{mAs}$ ) and has been converted into virtual 3dimensional images, then send it to the centre for advanced manufacturing technology (Biomedical Institute Wuhan Hubei Province). Firstly, the mandible and iliac 


\section{Global Journal of Otolaryngology}

crest bone were segmented according to the defects of recipient site and then 3D radiological examination and evaluation were done. We performed virtual mandibulectomy according to clinical and 3D radiological examination (shown Figure 1). The donor site was segmented, and we superimposed the 3D iliac image on the lateral mandibular defects in this case to have a neo mandible contour form (Figures $2 \& 3$ ).

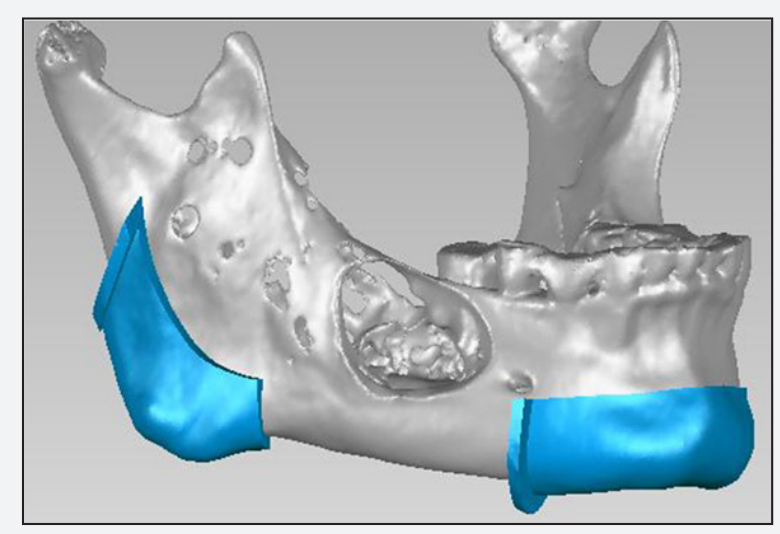

Figure 1: Fabrication of the reconstructed mandibular stereomodel with cutting template fixed (proximal and distal) to the defect for resection of tumor.

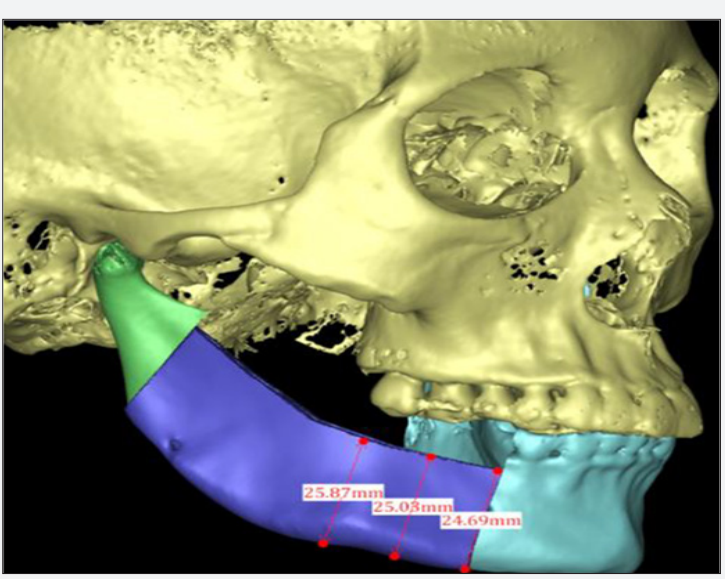

Figure 2 : Mandibular reconstruction with iliac crest on proplan software.

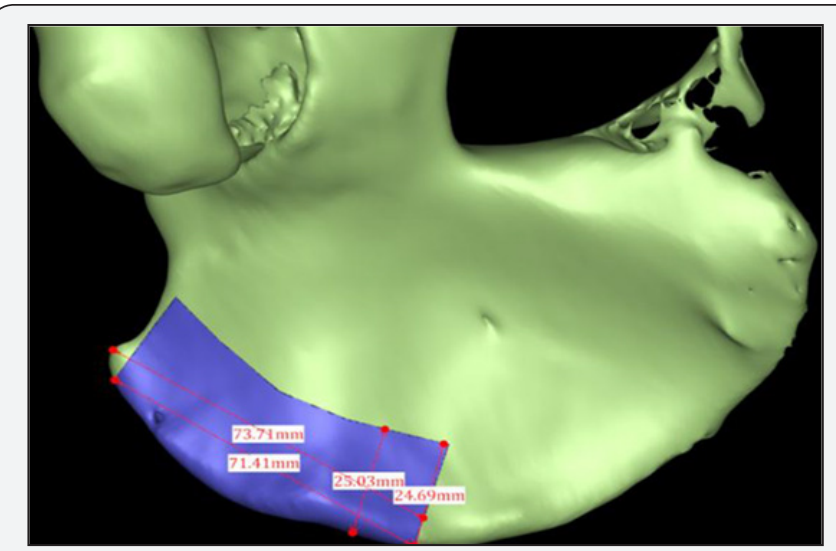

Figure 3 : Segmentation of donor iliac crest.
When the tumour has destroyed the contour of the mandible the unaffected side was used to form the ideal mandibular contour. A computer-assisted virtual surgical planning was generated, and an ideal reconstructed stereo model was manufactured using 3D printing technology. A reconstruction plate was pre-bent and fixed on the reconstructed mandibular model using titanium screws. The donor site was printed as a model in order to make an iliac crest cutting template to guide the harvest and molding of the iliac bone. Although the mandibular model with the reconstruction plate was subjected to CT scanning and the data were imported to the Pro plan CMF software in DICOM format. The model was segmented with the reconstructed mandible that we made previously, which is virtually designed and six points positions of titanium screws were marked for the accuracy of locating the plate during the operation.

\section{Surgical Procedure}

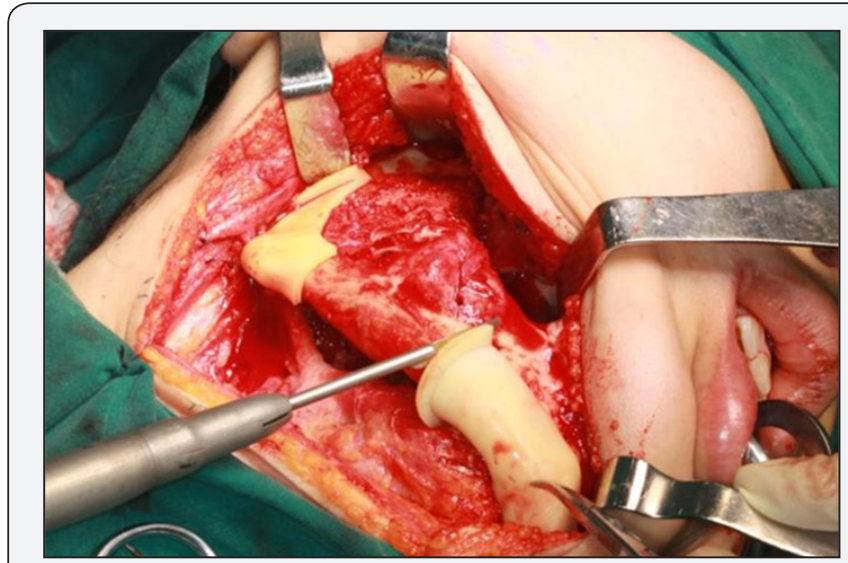

Figure 4 : Intra operative showing resection of tumor using cutting template (Proximal and distal to the defect).

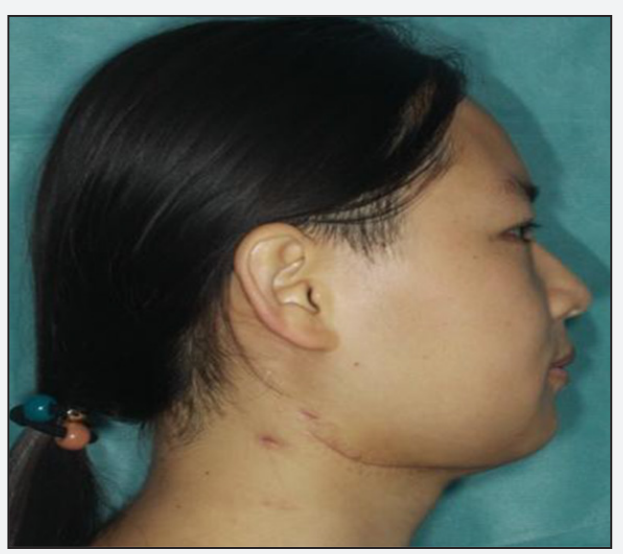

Figure 5 : Postoperative profile view of patient after 6 months.

The iliac crest flap was harvested as described by Taylor et al. [6], immediately with the mandibulectomy. The flap was molded using the resin model and cutting template (Figure 4) then transferred to the recipient site and the micro vascular anatomises was done using a coupler. For conventional surgery 
group, segmental resection and mandibular reconstruction were based on the surgeon's experiences without any design of preoperative surgical planning to perform the operation and the probability of error would always exist [7]. The flap was fixed to the mandibular segment with reconstruction plate or mini plate based on the surgeon's decision (Figure 5). Postoperative conventional technique for flap monitoring method that was used includes clinical examination and observation supplemented beside external Doppler every 30 minutes for the first $24 \mathrm{~h}$, every one hour for the next $24 \mathrm{~h}$ and every $4 \mathrm{~h}$ in the following days. Postoperative CT scan was performed for all 42 patients and followed up at one, three, six, and one year after discharge home. Complications such as plate breakage, infections of donor sites, recipients sites and flap loss were not encountered.

\section{Statistical Analysis}

Fisher's exact test and statistical analysis were performed using SPSS 17.0 software (SPSS INC, Chicago, Illinois USA). The $P$ value was less than or equal to 0.05 . The events were accepted as significant. However, there is no statistical significance between independent factors (age, tumour, sites of defects) and dependent factor (days of staying in the hospital).

\section{Results}

We treated 42 patients with tumour diseases and traumatic defects. The mean age was $38.50 \pm 14.74$ years and for those who underwent reconstruction based on computer-assisted surgery, the mean age was $30.07 \pm 13.72$ years. The overall flap survived successfully without any complications in both groups. The condyle was preserved and clinical outcomes (appearance of facial, opening mouth and temporomandibular joint) of all patients were satisfactory postoperatively (Figure 5). However, for a patient with conventional surgery, there was a malposition of the bone to the recipient site. The days of staying in the hospital and operation time of the two groups of patients were compared. Those in computer- assisted group presented with a short time of operation than the conventional surgery: $(7.00 \pm 1.62) /(8.61 \pm 1.40)$ respectively with a P value $(\mathrm{p}=0.002)$.

However, for patients who underwent conventional surgery, the days of staying has decreased than the computer-assisted surgery: $(17.32 \pm 4.78) /(21.21 \pm 3.53)$ with $(\mathrm{P}=0.010)$. The result indicated that patients in computer-assisted surgery presented a short time in operation than the conventional surgery group. Moreover, the conventional surgery group had short days of staying in the hospital due to benign tumours. For the computerassisted group, days of staying in the hospital increased due to malignant tumours and radiotherapy before surgery.

\section{Discussion}

Several options for mandibular reconstruction are available, among which the vascularised iliac crest flap has exhibited many advantages for patients. Achieving functional and esthetic goals solely on the basis of experience is difficult for surgeons and computer-assisted techniques such as virtual surgical planning can here resolve this problem to improve the clinical outcomes. In this study, we used computer-assisted surgery for 14 patients with defects of lateral mandible body and 28 patients treated with conventional surgery based on the experience of the author to perform the operation. The advantages of the computerassisted technique are that it can be used for the preoperative plan, allowing surgeons to complete accurate ablation and reconstruction and also operation time decreases $[8,9]$.

In our study all patients treated by conventional surgery were benign tumours with clear margins of the jaw which require segmental resection and those who underwent computerassisted surgery were malignant and benign tumours. However computer-assisted method must be applied with caution for malignant tumours and the disadvantage of this method is the cost-effectiveness for the patient in poor condition. For patients who underwent conventional of mandible reconstruction with the iliac crest free flap, mandibulectomy, flap harvest and moulding, the reconstruction procedure was based on the surgeon's experience. The acceptable result was achieved and most patients in this group were satisfied postoperatively. With the help of computer-assisted surgery, short time of operation was achieved than those of conventional surgery.

This technique has a positive impact on the reconstruction of mandibular defects through the provision of the accuracy of the graft placement that allows the surgical team to visualize the resection and reconstruction options which can provide the best outcomes and limit possible complications $[10,11]$. Recently, many surgeons have reported the applications of computer-assisted techniques for maxillary and mandibular reconstruction with free fibula flap with more accurate reconstruction than conventional surgery [12-14]. In this study the computer-assisted group presented good result, however, the days of staying in the hospital increased due to a malignant tumour and radiotherapy preoperatively. There is no statistical significance between the two groups of patients treated due to the small number of patients enrolled in this study; future more cases should improve the result.

CAD/CAM guides and navigation system are two methods used for transferring the preoperative virtual design to real surgery on the patients. Nowadays, all types of resection and cutting guides have become useful and popular in mandibular reconstruction surgery. Furthermore, a patient- specific CAD/CAM reconstruction plate, resection and cutting guides were introduced for reconstruction $[15,16]$. They provided a broad range of opportunities and advantage for mandibular reconstruction in patients compared to conventional surgery procedure. For conventional surgery group, there is no virtual plan or navigation, and mandibulectomy and reconstruction heavily depended on the experience of surgeons without any accuracy control. Shaw et al. [17] compared the effect of mandible reconstruction with both reconstruction and mini 
plates and they suggested that no significant difference between the two methods with respect to fixation and complications.

In our study, all patients in both group reconstruction plates and mini plates were used for fixation and no complications have been encountered. In conventional surgery, inter maxillary fixation is usually used to maintain the mandibular position and it depends only on the expertise of the surgeons. In the case where computer-assisted techniques are used, it provides more surgical convenience, but the preoperative plan was more time consuming, and it comes along with higher total costs of the procedure ( virtual planning and manufacture of the model costs around 1000-1500\$). There is also a possibility of the higher radiation dosage to the patient due to the CT scanning criteria, and planning and manufacturing time take a minimum of three days. This can have an impact on patients with oncological and traumatic defects. However, many reports [18-22] in the literature have been done often regarding the cost-effect of this technique and it is considered worthwhile due to the reduction of operation time, reduced complications and a better anatomical and functional results. Computer-assisted virtual planning has become a guide for surgeons. A judicious selection of patients based on the expected surgical utility is very important.

\section{Conclusion}

Computer-assisted virtual surgical planning can be done to the satisfaction of the patient using the iliac crest flap and conventional surgery. With the experience of the surgeon's osteotomy with freehand, good results were achieved. However, in our experience the best indication for computer- assisted surgery should be for the benign tumour with clear margins.

\section{References}

1. Brown JS, Barry C, Ho M, Shaw R (2016) A new classification for mandibular defects after Oncological resection. Lancet Oncol 17(1): e23-e30.

2. Urken ML (1991) Composite free flaps in oromandibular reconstruction. Review of the Literature. Arch Otolaryngol Head Neck Surg 117(7): 724-732.

3. Muno Z Guerra MF, Gias LN, Rodriguez Campo FJ, Diaz Gonzalez FJ: Vascularized free fibular flap for mandibular reconstruction: a report of 26 cases. Journal of Oral Maxillfac Surg 59(2): 140-144.

4. Lyons AJ, James R, Collyer (2005) Free Vascularized iliac crest graft: an audit of 26 consecutive cases .Br J oral Maxillofac Surg 43(3): 210-214.

5. Navarro Cuellar C, Caicoya SJ, Acero Sanz JJ, Navarro Cuellar I, Muela CM, et al. (2014) Mandibular reconstruction with iliac crest free flap, nasolabial flap, and Osseointegrated implants. J Oral Maxillofac Surg 72(6): 1226e1-1226e15.

6. Taylor GI, Townsend, P, Corlett R (1979) Superiority of the deep circumflex iliac vessels as the supply for free groyne flaps. Plast Reconstr Surg 64(6): 745-759.
7. Wang TH, Tseng CS, HsiechCy, MaH, Shen BH, et al. (2009) Using computer-aided design paper model for mandibular reconstruction: a preliminary report. Journal of Oral Maxillofac Surg 67: 2534-2540.

8. Eckardt A, Swennen GR (2005) Virtual planning of composite mandibular reconstruction With free fibula bone graft. J Craniofacial Surg 16: 1137-1140.

9. Shen Y, Sun J, LiJ, JiT, LiMM. A revised approach for mandibular reconstruction with vascularized iliac crest flap by virtual surgical planning. Plast Reconstr Surg In press.

10. Gateno J, Xia JJ, Teichgraeber JF, Christensen AM, Lemoine JJ, et al. (2007) Clinical feasibility of computer aided surgical simulation (CASS) in the treatment of complex Cranio-maxillofacial deformities. Journal of Oral Maxillofac Surg 65(4): 728-734.

11. Troulis MJ, Everett P, Seldin EB, Kikinis R, Kaban LB (2002) Development of a three-dimensional treatment planning system based on computed tomographic data. Int J Oral Maxillofac Surg 31(4): 349-357.

12. Hohlweg Majert B, Schon R, Schmelzeisen R, Gellrich NC, Schramm A (2005) Navigational Maxillofacial Surgery using virtual models. World J Surg 29: 1530-1538.

13. Bell RB (2010) computer planning and intraoperative navigation in Cranio-maxillofacial surgery. Oral Maxillofac Surg Clin North Am 22(1): 135-156.

14. Austin RE, Antonyshyn OM (2012) Current application of 3D intraoperative navigation in Craniomaxillofacial surgery: a retrospective clinical review. Ann Plast Surg 69(3): 271-278.

15. Wilde F, Cornelius CP, Schramm A (2014) Computer-assisted mandibular reconstruction using a patient specific reconstruction plate fabricated with computer-aided design and manufacturing techniques. Craniomaxillofac Trauma Reconstr 7(2): 158-166.

16. Wilde F, Hanken H, Probst F, Schramm A, Heiland M, et al. (2015) Multicenter study on the use of patient-specific CAD/CAM reconstruction plate for mandibular reconstruction. Int J Comp Assist Radiol Surg 10(12): 2035-2051.

17. Shaw RJ, Kanatas AN, Lowe D, Brown JS, Rogers SN, et al. (2004) Comparison of miniplates and reconstruction plates in mandibular reconstruction. Head Neck 26: 456-463.

18. D'Urso PS, Barker TM, Earwaker WJ, Bruce LJ, Atkinson RL, et al. (1999) Stereolithographic biomodelling in Craniomaxillofacial surgery: a prospective trial Journal of Cranio Maxillofac Surg 27(1): 30-37.

19. Josip S Bill, Jürgen F Reuther, Werner Dittmann, Norbert Kübler, Josef L Meier, et al. (1995) stereolithographic in oral and Maxillofacial operation planning. Int Journal of Oral Maxillofac Surg 24(1): 98-103.

20. Sailer HF, Haers PE, Zollikofer CP, Warnke T, Carls FR, et al. (1998) The Value of stereolithographic Models for preoperative diagnosis of craniofacial deformities and planning of surgical Corrections. Int Journal of Oral Maxillofac Surg 27(5): 327-333.

21. Xia JJ, Phillips CV, Gateno J, Teichgraeber JF, Christensen AM, et al. (2006) Cost- effectiveness analysis for computer aided surgical simulation in complex Cranio-maxillofacial surgery. Journal of Oral Maxillofac Surg 64(12): 1780-1784.

22. D'Urso PS, Atkinson RL, Lanigan MW, Earwaker WJ, Bruce IJ, et al (1998) Stereolithographic (SL) biomodelling in Craniofacial Surgery. Br J Plast S 51(7): 522-530. 
This work is licensed under Creative Commons Attribution 4.0 License

DOI: $10.19080 / G J O .2018 .13 .555872$

\section{Your next submission with Juniper Publishers} will reach you the below assets

- Quality Editorial service

- Swift Peer Review

- Reprints availability

- E-prints Service

- Manuscript Podcast for convenient understanding

- Global attainment for your research

- Manuscript accessibility in different formats ( Pdf, E-pub, Full Text, Audio)

- Unceasing customer service

Track the below URL for one-step submission https://juniperpublishers.com/online-submission.php 